\title{
Does Fear of Falling Relate to Low Physical Function in Frail Elderly Persons?: Associations of Fear of Falling, Balance, and Gait
}

\author{
Yumi HiguCHI ${ }^{1}$, Hiroaki SUdO ${ }^{2}$, Noriko TANAKA ${ }^{1}$, Satoshi FuCHIOKA ${ }^{1}$ and Yoshitaka HAYASHI ${ }^{1}$ \\ ${ }^{1}$ Department of Physical Therapy, Faculty of Comprehensive Rehabilitation, Osaka Prefecture College of Nursing, Osaka 583- \\ 8555, Japan \\ ${ }^{2}$ Department of Rehabilitation Medicine, Health Care Facility Mahoroba, Osaka 583-0857, Japan
}

\begin{abstract}
Falls are a major public health problem for older people. Recent research suggests that fear of falling may be a more pervasive and serious problem than falls among the elderly. The present study was conducted to determine whether frail elderly persons with fear of falling have lower physical function. A total of 47 subjects (aged 73 to 95) were recruited from a geriatric health services facility in Osaka. Physical function including balance, mobility, and muscular strength were measured using the following tests: Timed up \& go test (TUG), functional reach test, single limb stance with eyes open, ten-meter walk, and knee extensor strength. Twenty-nine subjects (62\%) had fear of falling and 18 $(38 \%)$ had no fear of falling. There was no significant difference in age, sex, or the proportion using assistive devices. Results from the statistical tests showed that there were no differences in physical function, except in the functional reach test. The ratio of TUG to $10 \mathrm{~m}$ walk was used to determine the association between balance and mobility. In frail elderly persons with fear of falling and in those without fear of falling, the means of the ratios were $1.20(\mathrm{SD}=0.27)$ and $1.03(\mathrm{SD}=0.16)$, respectively. The ratios for frail elderly persons with fear of falling were higher $(p=0.024)$ than the frail elderly without fear of falling. Our study suggests that even if frail elderly individuals walk slowly, they are not afraid of falling if there is a feasible balance function. We conclude that, in low-functioning frail elderly, fear of falling is associated with a combination of balance function and gait speed.
\end{abstract}

Key words: fear of falling, frail elderly, balance, gait speed

(J Jpn Phys Ther Assoc 7: 41-47, 2004)

F alls are a major public health problem for older people. With advancing age there is an increased incidence of falls and fall-related injuries. Fear of falling is defined by Tinetti and Powell ${ }^{1)}$ as a lasting concern about falling that leads an individual to avoid activities that he/she remains capable of performing, and this fear contributes to the probability of further falls. In a prospective study, falls were an independent predictor for developing fear of falling, and fear of falling was a predictor of falling ${ }^{2}$. This fear can also develop in individuals who have not experienced any falling episodes ${ }^{3)}$. In community-dwelling elderly persons, $43 \%$ reported having fear of falling, and $44 \%$ of them

Received: August 25, 2003

Accepted: February 7, 2004

Correspondence to: Yumi Higuchi, Department of Physical Therapy, Faculty of Comprehensive Rehabilitation, Osaka Prefecture College of Nursing, 3-7-30 Habikino, Habikino-city 583-8555, Japan reported activity restriction ${ }^{4}$. Almost half of older adults transitioning to frailty were concerned about fear of falling ${ }^{5)}$. Among women who visited the Fall Prevention Clinic in Tokyo, $85.4 \%$ had fear of falling, and $34 \%$ of them had restricted outdoor activities. In addition, they reported reduced one-leg balance with eyes open, reduced results in the timed up \& go test, and reduced leg strength ${ }^{6}$.

Recent research implicates fear of falling as a contributor to physical dependence among elderly persons ${ }^{1)}$. It is probable that fear of falling is a more pervasive and serious problem than falls in the elderly ${ }^{7)}$. Several studies have confirmed that fear of falling is associated with functional decline. Among ambulatory and independent elderly, those who expressed a fear of falling exhibited significantly poorer performance in the blindfolded spontaneous-sway tests and in the one-leg stance with eyesopen test ${ }^{8)}$. Other studies ${ }^{9) 10)}$ supported the close 
association between functional balance and fear of falling.

Frailty, defined as a reduction in physiological reserves ${ }^{11)}$, and behavioral capacities ${ }^{12)}$ can affect individuals as they age; that is, older individuals have lower levels of physical function. Kressig et al. ${ }^{5)}$ reported on a significant inverse correlation between fear of falling and balance among older adults transitioning to frailty. However, few studies have defined associations between fear of falling and physical function in frail elderly persons.

Our clinical experience indicated that some frail elderly persons have confident behavior in daily life, even if they walk slowly. We assumed that for these elderly, it is not necessarily true that low physical function is associated with fear of falling. The purpose of the present study was to determine whether frail elderly persons with fear of falling have lower physical function. Our hypotheses were that low levels of balance, mobility and strength themselves would not be sensitive factors in the development of fear of falling in frail elderly persons, and that the relationship between balance and mobility would be a specific and sensitive factor in the development of fear of falling.

\section{Method}

\section{Subjects}

A sample of frail elderly subjects was recruited from a geriatric health services fa'cility in Osaka. Inclusion criteria was the ability to walk with or without assistive devices and the disability score for dementia of rank I or better, which approved by the Ministry of Health and Welfare of Japan and means independent in daily life activities with slight dementia. Subjects who satisfied the criteria were asked for their consent to participate. At that time the activities involved with each clinical measure were explained, and informed consent was obtained. In addition, the physical therapist and nurse in charge of each potential subject were contacted to determine problems that would preclude participation in the study.

There were a total of 47 subjects ( 38 females, 9 males). They ranged in age from 73 to 95 years with a mean age of 83.3 years. Twenty-eight $(60 \%)$ were admitted to the facility, and 19 (40\%) were outpatients. The participants' main diagnoses are presented in Table 1.

Prior to participation, to measure fear of falling, the question "Are you afraid of falling?" was used with a yes/ no response format ${ }^{13)}$. Responses to the simple question about the presence of fear of falling correlate with the Tinetti Falls Efficacy Scale (FES) and have similar predictive validity ${ }^{14)}$. Individuals were characterized as fearful or not fearful based on the above question. Body weight was recorded for each subject prior to beginning the clinical measures.
Table 1. Sample characteristics $(n=47)$ main diagnoses

\begin{tabular}{ll}
\hline Variable & \\
\hline Low back pain & $9(19 \%)$ \\
Knee osteoarthritis & $7(15 \%)$ \\
Stroke & $6(13 \%)$ \\
Fracture & $5(11 \%)$ \\
Spondylarthritis & $5(11 \%)$ \\
Parkinson's disease & $1(2 \%)$ \\
Diabetes & $1(2 \%)$ \\
RA & $1(2 \%)$ \\
Others & $4(9 \%)$ \\
None & $8(17 \%)$ \\
\hline
\end{tabular}

\section{Clinical measures}

Physical function was measured by five items including balance, mobility, and muscular strength. Balance was evaluated using the timed up \& go test, functional reach, and single limb stance with eyes open. The timed up \& go test (TUG) ${ }^{15)}$ was originally developed as a clinical measure of balance in elderly people. It measures the time it takes a subject to stand up from an armchair, walk a distance of 3 $\mathrm{m}$, turn, walk back to the chair, and sit down at a comfortable and safe pace ${ }^{15)}$. If necessary, the subjects used their customary walking aids. Functional reach ${ }^{16)}$ is a dynamic measure of stability during a self-initiated movement. Functional reach was defined as the distance one can reach forward beyond arm's length while maintaining a fixed base of support while standing. A safety handrail was mounted just in front of the subject. The single limb stance with eyes open was assessed and timed by asking the individual to stand on his/her preferred leg with eyes open, hands placed on waist, and feet close to each other but not folded. Mobility was evaluated by measuring the length of time required to walk the middle 10 meters of a 13-meter walk at a comfortable pace. During the functional test of balance and mobility the experimenter stood directly behind the subject. Muscular strength was measured by assessing unilateral knee extensor strength. This was performed by using a hand-held dynamometer (MUSCULATOR GT-10, OG GIKEN CO., LTD, Okayama, Japan) with knee flexion at $60^{\circ}$ in a sitting position. The dynamometer placement was on the front of lower leg just proximal to ankle. The force gauge of the dynamometer was properly zeroed before each measurement according to the manufacturer's recommended procedure. It can measure forces from 0.0 to $30.0 \mathrm{~kg}$ to the nearest $0.1 \mathrm{~kg}$. The value was calibrated using known body weights. On each performance, the subjects tried the test once before they were timed. The best physical function of two trials on each test was recorded. 
Table 2. Demographics of subjects according to group

\begin{tabular}{lcccc}
\hline Variable & $\begin{array}{c}\text { Fearful } \\
(\mathrm{n}=29)\end{array}$ & $\begin{array}{c}\text { Not fearful } \\
(\mathrm{n}=18)\end{array}$ & P-Value & $\begin{array}{c}\text { Total } \\
(\mathrm{n}=47)\end{array}$ \\
\hline Age (years) & & & & \\
Mean & 84.3 & 81.7 & 0.210 & 83.3 \\
SD & 5.0 & 9.0 & & 6.9 \\
$\quad$ Range & $77-95$ & $73-95$ & & $73-95$ \\
Sex & & & & $38(81 \%)$ \\
Female & $23(79 \%)$ & $15(83 \%)$ & 0.524 & $26(55 \%)$ \\
Assistive device & & & & $13(28 \%)$ \\
None & $18(62 \%)$ & $8(44 \%)$ & & $8(17 \%)$ \\
Cane & $7(24 \%)$ & $6(33 \%)$ & 0.490 & $18(38 \%)$ \\
$\quad$ Walker & $4(14 \%)$ & $4(22 \%)$ & & 0.016 \\
Fall(s) in previous year & $15(52 \%)$ & $3(17 \%)$ & & \\
\hline
\end{tabular}

Table 3. Physical function described by gender

\begin{tabular}{|c|c|c|c|}
\hline & $\begin{array}{l}\text { Male } \\
(\mathrm{n}=9)\end{array}$ & $\begin{array}{l}\text { Female } \\
(\mathrm{n}=38)\end{array}$ & $\begin{array}{l}\text { Total } \\
(\mathrm{n}=47)\end{array}$ \\
\hline Variable & Mean \pm SD & Mean $\pm \mathrm{SD}$ & Mean $\pm \mathrm{SD}$ \\
\hline \multicolumn{4}{|l|}{ Balance* } \\
\hline Timed up \& go test (sec) & $20.3 \pm 10.2$ & $20.2 \pm 10.4$ & $20.2 \pm 10.2$ \\
\hline Functional reach test $(\mathrm{cm})$ & $13.6 \pm 7.2$ & $12.2 \pm 7.3$ & $12.4 \pm 7.2$ \\
\hline Single limb stance with eyes-opened (sec) & $2.1 \pm 4.2$ & $2.0 \pm 2.7$ & $2.1 \pm 3.0$ \\
\hline \multicolumn{4}{|l|}{ Mobility* } \\
\hline Ten-meter walk (sec) & $17.6 \pm 8.25$ & $19.2 \pm 10.6$ & $18.9 \pm 10.1$ \\
\hline \multicolumn{4}{|l|}{ Strength* } \\
\hline Right knee muscle strength /wt (kg/wt) & $0.27 \pm 0.10$ & $0.25 \pm 0.05$ & $0.25 \pm 0.08$ \\
\hline Left knee muscle strength /wt (kg/wt) & $0.25 \pm 0.10$ & $0.25 \pm 0.07$ & $0.25 \pm 0.08$ \\
\hline
\end{tabular}

*No significant difference $(\mathrm{p}<.05)$ between groups.

\section{Statistical analysis}

Descriptive statistics were used to identify the mean and standard deviation of all outcome variables. Statistical tests, Student's t-test for two-group comparison and chisquare tests for proportions, were used. The significance level was set at .05 , and the statistical analysis was accomplished by using the SPSS 10.0J software package.

\section{Results}

Out of a total of 47 subjects, $29(62 \%)$ had fear of falling and 18 (38\%) had no fear of falling (Table 2). For those with fear of falling, the mean age was 84.3 years, and for those without fear the mean was 81.7 years. Forty-five percent of the sample required the use of assistive devices for ambulation. There were no significant differences between the two groups in age, sex, or the proportion of subjects using assistive devices. Thirty-eight percent of the sample reported having fallen in the previous year, and the group with fear of falling reported significantly more falls in the past one year.

\section{Gender and physical function}

Table 3 presents physical function data in frail elderly persons grouped by gender. There were no significant differences in balance, mobility, and strength (adjusted by body weight).

\section{Influence of fear of falling on physical function}

Table 4 compares the physical function of frail elderly persons with fear of falling and that of frail elderly persons without fear of falling. Results from the statistical tests showed that there were no differences in TUG, single limb stance with eyes open, ten-meter walk and unilateral knee muscle strength adjusted by body weight. There were differences in functional reach $(\mathrm{p}=.048)$. Figure 1 shows 
Table 4. Comparison of physical function in frail elderly persons with fear of falling and without fear of falling

\begin{tabular}{lccc}
\hline \multicolumn{1}{c}{ Variable } & $\begin{array}{c}\text { Fearful } \\
(\mathrm{n}=29)\end{array}$ & $\begin{array}{c}\text { Not fearful } \\
(\mathrm{n}=18)\end{array}$ & p-Value \\
\hline & Mean $\pm \mathrm{SD}$ & Mean $\pm \mathrm{SD}$ & \\
\hline Balance & & & \\
$\quad$ Timed up \& go test (sec) & $21.3 \pm 11.4$ & $18.5 \pm 8.1$ & 0.376 \\
$\quad$ Functional reach test (cm) & $14.1 \pm 7.1$ & $9.74 \pm 6.6$ & 0.048 \\
$\quad$ Single limb stance with eyes-opened (sec) & $2.5 \pm 3.4$ & $1.3 \pm 1.9$ & 0.187 \\
Mobility & & & 0.902 \\
$\quad$ Ten-meter walk (sec) & $19.0 \pm 10.5$ & $18.6 \pm 9.8$ & \\
Strength & & & 0.432 \\
$\quad$ Right knee muscle strength $/ \mathrm{wt}(\mathrm{kg} / \mathrm{wt})$ & $0.25 \pm 0.08$ & $0.27 \pm 0.08$ & 0.653 \\
$\quad$ Left knee muscle strength /wt (kg/wt) & $0.24 \pm 0.08$ & $0.25 \pm 0.08$ & \\
\hline
\end{tabular}

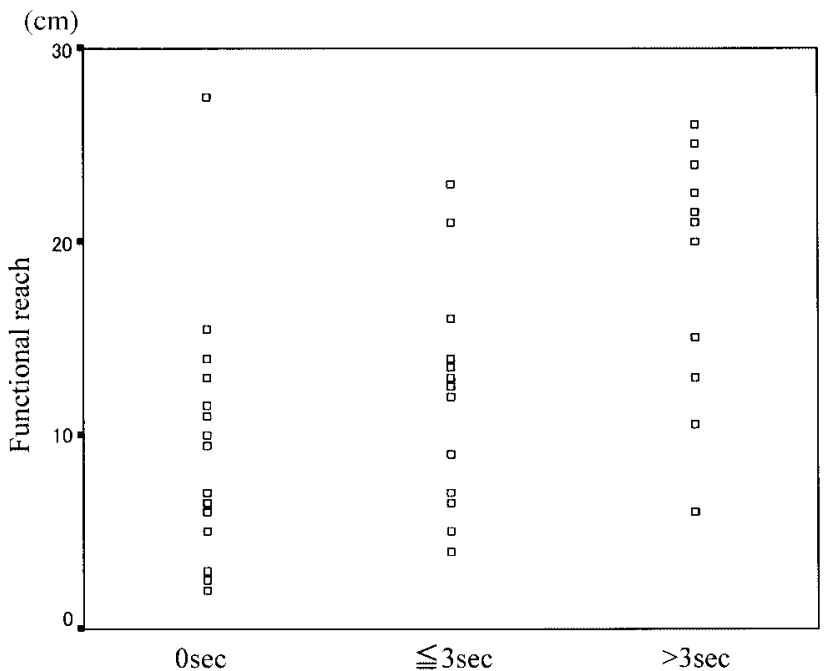

The time of single limb stance (sec)

Fig. 1. Relationship between the functional reach and the time of single limb stance with eyes open.

the distribution of functional reach in subjects who were unable to perform the single limb stance (0 seconds), subjects who balanced for at least 3 seconds, and subjects who balanced for over 3 seconds. One subject in the unable-to-balance group had the best record of $27.5 \mathrm{~cm}$ in the functional reach, and this record was distributed out of the trend the others were showing. With the exception of the subject's data, the mean of functional reach for the fearful group was $13.6 \mathrm{~cm}$, and there were no differences in the two groups statistically $(\mathrm{p}=0.071)$.

\section{Association between balance and mobility and its relation to fear of falling}

Figure 2 presents the difference in fear of falling

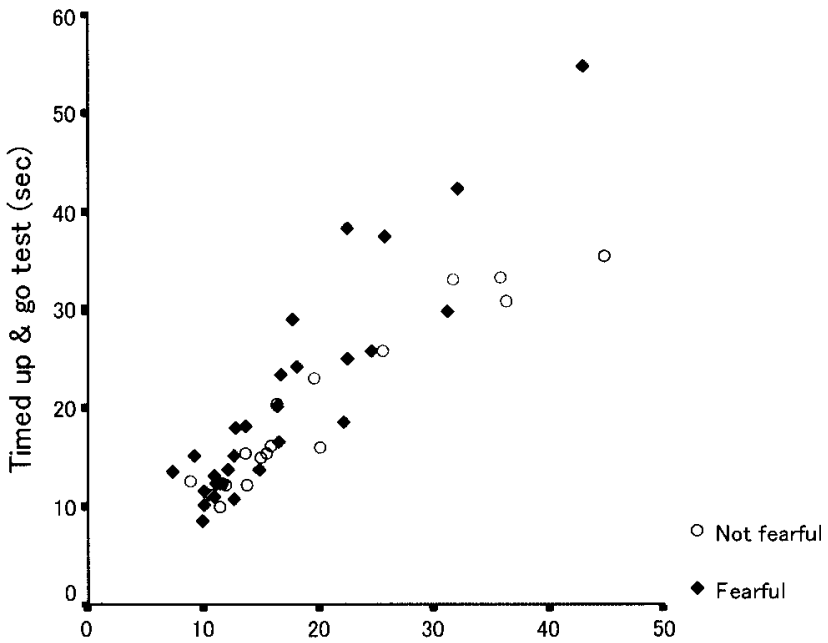

Ten-meter walk (sec)

Fig. 2. The association between Timed up \& go test and $10 \mathrm{~m}$ walk test.

according to the association between TUG and the $10 \mathrm{~m}$ walk. Another way of determining whether the difference occurred was to compare the ratio of TUG to $10 \mathrm{~m}$ walk in those who have fear of falling with the ratio in those without fear of falling (Fig. 3). Higher values of the ratio indicated less physical dysfunction of balance compared with his/her mobility. For example, in case of the same gait speed, the person who performed TUG faster obtained lower values of the ratio. Figure 3 shows that the mean of the ratios was $1.20(\mathrm{SD}=0.27)$ for those with fear, and 1.03 $(\mathrm{SD}=0.16)$ for those without fear. The ratio for those with fear of falling was higher significantly $(p=0.024)$ than that for those without fear of falling. 


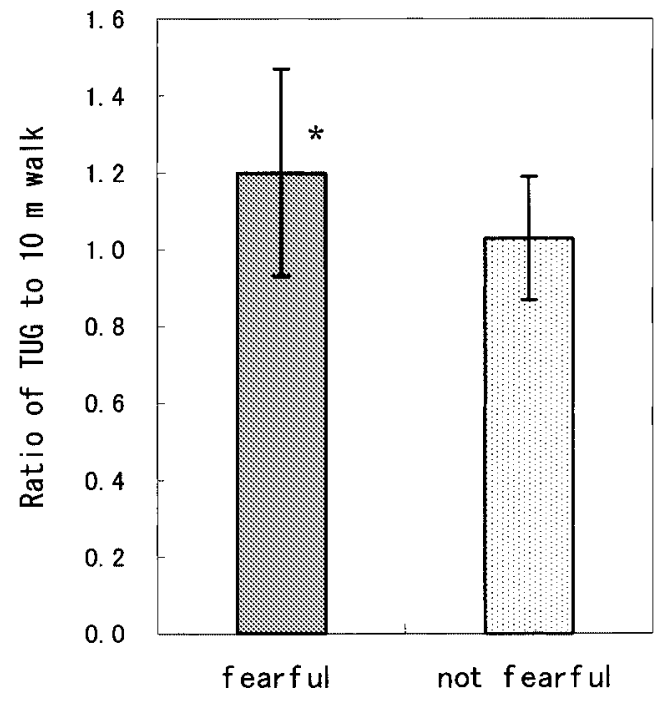

Fig. 3. Comparison of the ratio of TUG to $10 \mathrm{~m}$ walk in the group with fear of falling and the group without fear of falling $\left(\mathrm{t}=2.34,{ }^{*} \mathrm{p}<0.05\right)$.

\section{Discussion}

The elderly persons in this study, with means of approximately 20 seconds for TUG and $0.53 \mathrm{~m} / \mathrm{s}$ for gait speed (10 m walk test in 18.9 seconds), had lower physical function than community-dwelling elderly observed in previous studies where the mean of TUG was reported to be 9-14 seconds ${ }^{17) 18)}$ and gait speed was $1.15-1.38 \mathrm{~m} / \mathrm{s}^{19)}$. The mean of the functional reach in the present study was also much lower than that in elderly people with fear of falling ${ }^{5)}$.

In this study of frail elderly individuals aged 73 to 95 , we found that fear of falling did not distinguish those with low physical function from those with high function, whereas several studies have reported that fear of falling is associated with functional decline ${ }^{13}$. Maki et al. ${ }^{8)}$ reported that ambulatory and independent elderly people who expressed fear of falling performed significantly more poorly in the eyes-open one-leg stance test. In a study of outpatients of the Fall Prevention Clinic ${ }^{6}$, the group whose activity was restricted because of fear of falling had a significantly reduced performance in the eyes-open one-leg stance test. However, the participants of these studies functioned independently and were free from pathologies. Moreover Maki et al. ${ }^{8}$ reported that the means in the oneleg stance test were 6.8 seconds in the group with no fear of falling and 3.4 seconds in the group with fear of falling. The latter study showed that even the group whose activity was restricted because of fear of falling had a result of over 10 seconds in the one-leg stance test. Our single limb stance data in all subjects showed a mean of 2.1 seconds, which suggested that the previous reports investigated elderly people with a higher level of physical function than did the present study.

Kim et al. ${ }^{6}{ }^{6}$ reported that the group whose activity was restricted because of fear of falling had TUG results (a mean of 18.5 seconds) that were lower than those of the non-restricted group (11.9 seconds). The mean of our TUG data was just below 20.2 seconds. Podsiadlo ${ }^{15)}$ reported that the subjects who performed the test in less than 20 seconds tended to be independently mobile. Several studies confirmed that the longitudinal risk factors for falls were TUG $>16$ seconds, history of stroke, and depression ${ }^{20)}$. They also showed that TUG $>17$ seconds was one of the independent predictors of declines in $\mathrm{ADL}^{21)}$. It should be emphasized that the subjects of this paper had lower physical function than the subjects of previous reports, and our results thus indicated some of the functional characteristics of frail elderly persons.

Functional reach was the only physical function in which significant differences were observed between the fearful and not-fearful groups. As shown in Fig. 1, a subject who was unable to stand on one leg had the best record of $27.5 \mathrm{~cm}$ for functional reach. This record was distributed out of the trend the others were showing. A possible explanation relates to the fact that a safety handrail was mounted just in front of all subjects, whether they were fearful or not. In spite of we prohibited the subjects from touching the handrail, it may be that some subjects touched the safety handrail and kept their balance. The results suggested that it was difficult for the frail elderly people to perform the functional reach test safely and accurately.

In a recent study ${ }^{4}$, muscle strengthening and balance retraining were effective in reducing fall-related injuries and fear of falling in those aged 80 years and older. However, those researchers did not measure the actual muscle strength. In the study ${ }^{6}$ of outpatients of the Fall Prevention Clinic, those not only feeling fear of falling but also having their activity restricted because of the fear showed significantly reduced leg extension. The differences in characteristics between elderly persons who have no fear of falling, those who have fear of falling alone, and those with restricted activity due to a fear of falling were investigated ${ }^{22}$. The present study revealed the characteristics associated with fear of falling in frail elderly people and found no significant differences between the fearful and not-fearful groups.

Individuals who had fear of falling experienced more falls in the previous year. This supports that falls were an independent predictor of developing fear of falling ${ }^{2}$. Friedman et al. ${ }^{2}$ reported that an individual who had fear of falling or falls was at risk for developing the other because each was a risk factor for the other.

Declining balance and unsteady gait are major problems for the elderly ${ }^{23}$. Various studies have examined the effect of physical therapy on balance and mobility function in older people, and have suggested that 
appropriate exercise programs may be effective ${ }^{24)}$, resulting in a reduced risk of falling ${ }^{25) 26)}$. In a randomized study ${ }^{24)}$ of elderly subjects with balance dysfunction, individualized exercise programs were found to significantly improve balance and gait, but no significant difference was observed regarding fear of falling. Those results suggested that the independent results of balance and gait in the frail elderly mightn't be related to an improvement of fear of falling.

Therefore we originally used the ratio of TUG to the 10 $\mathrm{m}$ walk as an index that indicated the relationship between balance function and mobility. The results of this study confirmed that fear of falling was associated with the ratio of TUG to $10 \mathrm{~m}$ walk in the frail elderly. Our results were supported by the finding that, in the physical therapy evaluation of the elderly in residential care facilities, a combination of measuring balance and gait speed yielded the most promising results ${ }^{27)}$. Our results suggest that even if frail elderly individuals walk slowly, they are not afraid of falling if they have a feasible balance function.

The study may be limited by assessing fear of falling with a simple question. Although it was reported that responses to the simple question about the presence of fear of falling correlate with the Tinetti Falls Efficacy Scale (FES), recently many authors have used FES to quantify fear of falling or fall-related efficacy ${ }^{13)}$. However, we hesitate to use FES because the validity and reliability of a Japanese edition has not yet been verified. Some measurement tools of fear of falling in the Japanese edition should be established immediately.

We conclude that, in low-functioning frail elderly, fear of falling is associated with a combination of balance function and gait speed. The ratio of TUG to $10 \mathrm{~m}$ walk is a simple clinical assessment; we believe this indicator is a potentially useful measurement in frail elderly persons.

\section{References}

1) Tinetti ME, Powell L: Fear of falling and low self-efficacy; a cause of dependence in elderly persons. J Gerontol 48: 35-38, 1993.

2) Friedman SM, Munoz B, West SK, et al.: Falls and fear of falling; which comes first? A longitudinal prediction model suggests strategies for primary and secondary prevention. $\mathrm{J}$ Am Geriatr Soc 50: 1329-1335, 2002.

3) Silverton R, Tideiksaar R: Psychosocial aspects of falls. In: Falling in Old Age; Its Prevention and Treatment. New York, Springer, 1989, pp 87-110.

4) Robertson MC, Campbell AJ, Gardner MM, et al:: Preventing injuries in older people by preventing falls; a meta-analysis of individual-level data. J Am Geriatr Soc 50: 905-911, 2002.

5) Kressig RW, Wolf SL, Sattin RW, et al:: Association of demographic, functional, and behavioral characteristics with activity-related fear of falling among older adults transitioning to frailty. J Am Geriatr Soc 49: 1456-1462, 2001.

6) Kim H, Yoshida H, Suzuki T, et al.: The relationship between fall-related activity restriction and functional fitness in elderly women. Jpn J Geriat 38: 805-811, 2001(In Japanese).

7) Cumming RG, Salkeld G, Thomas M, et al:: Prospective study of the impact of fear of falling on activities of daily living, SF-36 scores, and nursing home admission. J Gerontol A Biol Sci Med Sci 55: M299-305, 2000.

8) Maki BE, Holliday PJ, Topper AK: Fear of falling and postural performance in the elderly. J Gerontol 46: M123$131,1991$.

9) Lawrence RH, Tennstedt SL, Kasten LE, et al.: Intensity and correlates of fear of falling and hurting oneself in the next year. J Aging Health 10: 267-286, 1998.

10) Li F, McAuley E, Fisher KJ, et al.: Self-efficacy as a mediator between fear of falling and functional ability in the elderly. $\mathrm{J}$ Aging Health 14: 452-466, 2002.

11) Buchner DM, Beresford SAA, Larson EB, et al: : Effects of physical activity on health status in older adults II. Interventional studies. Ann Rev Public Health 13: 469-488, 1992.

12) Lawton MP: A multidimensional view of quality of life in frail elders. In: The Concept and Measurement of Quality of Life in the Frail \& Elderly. San Diego, Academic Press, 1991, pp 4-27.

13) Legters K: Fear of falling. Phys Ther 82: 264-272, 2002.

14) Lachman ME, Howland J, Tennstedt $S$, et al.: Fear of falling and activity restriction: The survey of activities and fear of falling in the elderly. J Gerontol B Psychol Sci Soc Sci 53B: P43-P50, 1998.

15) Podsiadlo D, Richardson S: The timed "up \& go"; a test of basic functional mobility for frail elderly persons. J Am Geriatr Soc 39: 142-148, 1991.

16) Duncan PW, Weiner DK, Chandler J, et al.: Functional reach; a new clinical measure of balance. J Gerontol 45: M192-197, 1990.

17) Bruce DG, Devine A, Prince RL: Recreational physical activity levels in healthy older women; the importance of fear of falling. J Am Geriatr Soc 50: 84-89, 2002.

18) Steffen TM, Hacker TA, Mollinger L: Age- and genderrelated test performance in community-dwelling elderly people; six-minute walk test, Berg Balance Scale, Timed up \& go test, and gait speeds. Phys Ther 82: 128-137, 2002.

19) Rockwood K, Awalt E, Carver D, et al.: Feasibility and measurement properties of the functional reach and the timed up and go tests in the Canadian study of Health and aging. $\mathrm{J}$ Gerontol 55A: M70-73, 2000.

20) Okumiya K, Matsubayashi K, Nakamura T, et al.: The timed "up \& go" test is a useful predictor of falls in communitydwelling older people. J Am Geriatr Soc 46: 928-929, 1998.

21) Okumiya K, Matsubayashi K, Nakamura $T$, et al.: The timed "up \& go" test and manual button score are useful predictors of functional decline in basic and instrumental ADL in community-dwelling older people. J Am Geriatr Soc 47: 497498, 1999.

22) Murphy SL, Williams CS, Gill TM: Characteristics associated with fear of falling and activity restriction in community-living older persons. J Am Geriatr Soc 50: 516520, 2002.

23) Tinetti ME: Performance oriented assessment of mobility problems in elderly patients. J Am Geriatr Soc 34: 119-126, 1986. 
24) Wolf B, Feys H, Weerdt WD, et al:: Effect of physical therapeutic intervention for balance problems in the elderly; a single-blind, randomized, controlled multicentre trial. Clinical Rehabilitation 15: 624-636, 2001.

25) Tinetti WE, Baker DI, McAvey G, et al.: A multifactorial intervention to reduce the risk of falling among elderly people living in the community. N Engl J Med 331: 821-827, 1994.
26) Campbell AJ, Robertson C, Gardner MM, et al.: Falls prevention over 2 years; a randomized controlled trial in women 80 years and older. Age Aging 28: 513-518, 1999.

27) Harada N, Chiu V, Damron-Rodriguez J, et al.: Screening for balance and Mobility impairment in elderly individuals living residential care facilities. Phys Ther 75: 462-469, 1995. 